\title{
Structure and properties of xerogels derived from tannins and ethanol lignins of the Siberian Fir
}

\author{
Mikova N.M ${ }^{1}$., Levdansky V.A ${ }^{1}$., Skwortsova G.P ${ }^{1}$, Zhizhaev A.M ${ }^{1}$., Lutoshkin M.A ${ }^{1}$,, \\ Chesnokov N.V ${ }^{1}$., Kuznetsov B.N ${ }^{1,2}$. \\ ${ }^{1}$ Institute of Chemistry and Chemical Technology SB RAS, Federal Research Center "Krasnoyarsk Science Center \\ SB RAS", Krasnoyarsk, Russian Federation" \\ Russia, 660036, Krasnoyarsk, Akademgorodok, 50/24 \\ ${ }^{2}$ Institute of Non-Ferrous Metals and Materials Science, Siberian Federal \\ University, Krasnoyarsk, Russian Federation
}

\begin{abstract}
The organic xerogels, prepared from tannins and ethanol lignins of the fir (Abies sibirica), were synthesized for the first time. The influence of the composition of initial mixture and $\mathrm{pH}$ on the characteristics of xerogels obtained by sol-gel condensation of formaldehyde with polyphenols of fir has been studied. The possibility of regulating the density and porosity of gels by varying of the concentration of ethanol lignin in the initial mixture was established. It was found that tannin-lignin-formaldehyde gel with low-density $\left(0.11 \mathrm{~g} / \mathrm{cm}^{3}\right)$ and very high porosity $(92 \%)$ is formed at a mass ratio tannins and lignins equal 1. According to FTIR data the process of xerogels formation is carried out by crosslinking due to the formation carbon-carbon and alkyl ethers bonds. SEM method confirmed the formation of branched macromolecular structure of gels from interconnected spherical particles of different sizes. Thermogravimetric analysis demonstrates the greater thermal stability of tannin-formaldehyde gels compare to the tannin-lignin-formaldehyde gels. The increase of lignin concertation in gels more than $50-65 \%$ (by the mass) reduced the temperature of their intensive mass loss on $23-63^{\circ} \mathrm{C}$. The obtained organic gels are nonflammable polymers and they can be used as thermal and fire retardant materials.
\end{abstract}

Keywords: organic xerogels, syntheses, polyphenols of fir, structure, thermal properties.

\section{Introduction}

The organic and carbon gels are new perspective and unique polymeric materials. They are porous structured materials with three-dimensional mesh structure formed by the nanometers-scale particles [1-3]. The different ways of drying at the final-step of synthesis give various types of gels: aerogels, xerogels, and cryogels [4,5]. The traditional method of drying heating under atmospheric pressure leads to the formation of xerogels. Xerogel dried in air or in vacuum has the greater density and less porosity than aerogels or cryogels.

The chemical and thermal stability, high porosity of organic and carbon gels make these materials promising for use in medicine, catalysis [6], adsorption [7], and as the fuel cell capacitors $[8,9]$.

An urgent task is to improve the methods of organic gels synthesis by selection of nontoxic reagents and optimal conditions of gelation process. In the literature there are the examples of the use of natural polyphenolic compounds - condensed tannins and lignins for the preparation of gels by sol-gel condensation with formaldehyde [2,3,13,14]. 
The reactivity of macromolecules of tannins in crosslinking reactions with aldehydes is due to the presence of a large number of $\mathrm{OH}$-groups [12]. The tannins isolated from wood and bark of tropical varieties of mimosa and acacia (quebracho), are widely used as the available initial compounds for the preparation of the organic and carbon gels [2, 3,13,14].

Condensed tannins, also known as proanthocyanidins, are oligomers or polymers consisting of two or more units of 3,4-flavondiol or 3-flavonol (usually catechins or epicatechins) [15]. The structures of condensed tannins obtained from various raw materials differ in the content of $\mathrm{OH}$-groups in monomers units, in the ratio cis- and trans-monomers of catechin and epicatechin, and in the degree of polymerization [16].

Despite the specific differences in the structure and composition of flavonoid units the condensed tannins of quebracho, fir, spruce, are typical representatives of the phenolic substances of pyrocatechol group [17]. They have similar behavior in terms of their reactivity and tendency to cross-linking with formaldehyde in the synthesis of organic gels.

Organosolvent lignins, being chemically and structurally more homogeneous than technical lignins (for example, Kraft-lignin), are also attractive polyphenolic type raw materials for the preparation of polymer gels [18,19].

The biomass of coniferous trees has prospects for its use as a cheap and renewable raw material for the production of polyphenolic substances, represented by condensed tannins and lignin. The fir (Abies sibirica L.) is one of the main forest tree species in Russia. The bark of fir contains up to $9-13 \%$ by weight of tannins of catechin or flavan-3,4-diol nature monomer units which are mainly represented by proanthocyanidins and prodelphinidines.

In this work, for the first time, new polymer gels (xerogels) have been synthesized by condensation with formaldehyde of tannins and ethanol lignin isolated from fir bark and wood. The effect of the synthesis conditions of tannin-formaldehyde and tannin-lignin-formaldehyde xerogels on their structure and properties was studied.

\section{Experimental part}

To obtain gels, the polyphenolic compounds - condensed tannins and ethanol lignin were used. Tannins were extracted by ethanol from fir bark from which resinous substances were removed by diethyl ether. Ethanol lignin was isolated from fir wood by treating with $60 \%$ aqueous solution of ethanol in an autoclave at temperature of $170-190{ }^{\circ} \mathrm{C}$ according to the procedure described in [20].

Preparation of tannin-formaldehyde (TF) and tannin-lignin-formaldehyde (TLF) xerogels was carried out in ethanol. Polyphenolic compounds in required concentration were mixed with $37 \%$ formaldehyde aqueous solution at a mass ratio of $1.0: 1.5$. The concentration of initial 
components was varied in the range of tannin:lignin ratios 0.25-1.0:1.0-0.25. Sodium hydroxide, $\mathrm{HCl}$ and $\mathrm{HCOOH}$ were used to achieve an optimal $\mathrm{pH}$.

The solutions were kept in hermetically sealed glass tubes, at a temperature of $75^{\circ} \mathrm{C}$ for 5 days. Then the formed gels were extracted from tubes and placed in a flask with ethanol, this flask was shaken at $40^{\circ} \mathrm{C}$ for $72 \mathrm{~h}$. The ethanol was refreshed at each $24 \mathrm{~h}$. The obtained samples of gels were frozen at $-20{ }^{\circ} \mathrm{C}$ for 48 hours. After that, the samples were transferred to the freeze drying apparatus chamber, where the drying was performed at an operating pressure of $3.3 \mathrm{~Pa}$ and a temperature of $-44^{\circ} \mathrm{C}$.

FTIR spectra of samples were recorded in the region of $400-4000 \mathrm{~cm}-1$ on a Tensor 27 FTIR spectrometer (Brucker, Germany) in a potassium bromide matrix (5 mg / $1000 \mathrm{mg}$ of the matrix). Spectral information processing was performed using the OPUS software package, version 5.0.

The specific surface area and the porous volume of the samples of organic gels were determined by the physical adsorption of $\mathrm{N}_{2}$ at $77 \mathrm{~K}$ using a surface analyzer "Sorbtometr-M". Before measurements, the samples were trained for 2 hours at a temperature of $80{ }^{\circ} \mathrm{C}$. The apparent density of gels $\left(\mathrm{g} / \mathrm{cm}^{3}\right)$ was calculated from three parallel measurements based on the ratio of the weight of the sample to its volume.

The microstructure of the samples was studied by scanning electron microscopy in secondary electrons (S5500, Hitachi) and in back reflected electrons (TM-3000, Hitachi). The samples, the xerogels were fixed on the instrument table with two-sided conducting carbon tape and platinum was sprayed onto the surface using a K575X magnetron (Emitéch, England).

The weight average molecular weight $(\mathrm{Mw})$, number average molecular weight $(\mathrm{Mn})$ and the polydispersity of the samples were determined by gel permeation chromatography using an Agilent 1260 Infinity II Multi-Detector GPC/SEC System chromatograph. Data collection and processing were performed using Agilent GPC/SEC MDS software.

Thermogravimetric study of samples of organic gels was performed using the analyzer "Netzsch STA 449F1". The sample was heated in an argon atmosphere in an aluminum crucible from 400 to $800^{\circ} \mathrm{C}$ at a speed heating of $10^{\circ} \mathrm{C} / \mathrm{min}$. The elemental composition of the studied samples was determined using the HCNS-0 EA 1112 analyzer (Flash, USA).

\section{Results and discussion}

In this work, for the first time, we used a new source of polyphenolic compounds for synthesis of organic xerogels- tannins from fir bark, as an alternative of quebracho tannins. Widely used for the synthesis of organic aerogels tannins of quebracho contain from 80 to $82 \%$ phenolic flavonoids $[2,10,13]$. It was shown that the tannins from fir bark contain 92-95\% 
flavonoids, and the content of impurities is minimal. The high concentration of polyflavonoids in fir tannins was confirmed by their complete transformation into anthocyanidins during the heating of their alcohol solutions in the presence of acids[17].

The technical lignins (e.g. Kraft lignins [21]), used for synthesis of organic gels, have a high content of carbohydrates (from 0.5 to $1.5 \%$ ), sulfur (1-3\%) and mineral impurities (up to 1$3 \%$ ). Kraft lignins due to the hard conditions of their isolation are very heterogeneous in composition and are characterized by a large spread of molecular weight.

For Kraft lignins obtained from coniferous trees the molecular weight varies from 1100 to $39000 \mathrm{~g} / \mathrm{mol}$. The presence of high molecular weight fractions in samples of technical lignins degreases their solubility. To improve their solubility the more high temperature $\left(85-90^{\circ} \mathrm{C}\right)$ and concentrated solution of $\mathrm{NaOH}(20-30 \%)$ should be used.

Even such hard conditions do not provide full dissolution of technical lignin. Therefore, during the synthesis of gels, the lignin is precipitated in the powder form and does not participate in the process of condensation, but may be included into the forming gel in the form of a filler [22]. Such disadvantages are absent when using organosolv lignins [20].

Ethanol lignin obtained under milder conditions from fir wood is characterized by homogeneous structure and composition, does not contain sulfur, has a minimum content of associated organic substances and relativity small molecular weight. Ethanol lignin is fully soluble in a water-ethanol solution at room temperature.

Organic gels were prepared by condensation with formaldehyde of tannins and ethanol lignin, isolated from fir bark and wood. Tannin-formaldehyde (TF) gels were synthesized in acidic and alkaline media, and tannin-lignin-formaldehyde (TLF) gels were synthesized only in an acidic medium. In the synthesis of TLF gels, various mass ratios of tannins and ethanol lignin were used. In all cases, the ratio of the sum of the masses of tannins and lignin to the mass of formaldehyde was 1.0:1.5.

Table 1 shows the average data of elemental analysis and values of average molecular weight (- Mw), number average molecular weights $(\mathrm{Mn})$, and degree of polydispersity of fir tannins and ethanol lignin.

Table 1. Some characteristics of the fir polyphenols used to obtain organic xerogels

\begin{tabular}{|l|l|l|l|l|l|l|}
\hline Sample & $\begin{array}{l}\mathrm{C}, \\
\% \text { mass }\end{array}$ & $\begin{array}{l}\mathrm{H}, \\
\% \text { mass }\end{array}$ & $\begin{array}{l}\text { Ash content, \% } \\
\text { mass }\end{array}$ & $\begin{array}{l}\mathrm{M}_{\mathrm{W}}, \\
\mathrm{g} / \mathrm{mol}\end{array}$ & $\begin{array}{l}\mathrm{Mn}, \\
\mathrm{g} / \mathrm{mol}\end{array}$ & $\begin{array}{l}\text { Degree of } \\
\text { polydispersity }\end{array}$ \\
\hline Ethanol lignin & 66.34 & 5.94 & 0.37 & 1740 & 790 & 2.20 \\
\hline Tannins & 57.72 & 5.84 & 0.40 & 1884 & 684 & 2.75 \\
\hline
\end{tabular}


TF gels, obtained in acid media are solid and dense dark brown products, able to keep their shape at steps of extraction isolation and purification. However, after final drying in a vacuum they become brittle and break up into small fragments.

It is known that the capillary forces in the pores appeared at drying lead to shrinkage and compression of the material [23]. The replacement of the widely used of supercritical method drying with more cheap and simple method of drying under normal condition leads to the formation of organic gels with low porosity [2]. Drying xerogels in air or in vacuum creates large internal stresses in the material and contributes to its destruction $[4,5]$. It was found that the total porosity and density of the gels obtained from fir polyphenols are significant affected by the mass ratio of tannins and ethanol lignin in the initial reaction mixture.

The values of the apparent density $\left(\rho_{\mathrm{app}}, \mathrm{g} / \mathrm{cm}^{3}\right)$ and porosity $(\%$, relative) of organic gels, obtained at different ratios of tannins and ethanol lignin are given in Table 2. The density of the gel was determined as the ratio of the mass of finely ground gel to its volume.

Table 2. The values of the apparent density and porosity of organic gels derived from fir tannins and ethanol lignin.

\begin{tabular}{|l|l|l|l|l|l|l|l|l|}
\hline \multicolumn{7}{|c|}{ Mass ratio of tannins / ethanol lignin } \\
\hline & $1: 0$ & $1: 0,25$ & $1: 0,5$ & $1: 0,75$ & $1: 1,0$ & $1: 1,5$ & $1: 2,0$ & $0,25: 1,0$ \\
\hline $\begin{array}{l}\text { Lignin } \\
\text { concentration, \% }\end{array}$ & 0 & 20 & 30 & 43 & 50 & 60 & 67 & 80 \\
\hline$\rho_{\text {app }}, \mathrm{g} / \mathrm{cm}^{3}$ & 0,67 & 0,65 & 0,63 & 0,61 & 0,11 & 0,16 & 0,19 & 0,30 \\
\hline $\mathrm{W}, \%$ rel. & 52,5 & 53,9 & 55,3 & 57,2 & 92,2 & 88,6 & 86,5 & 78,7 \\
\hline
\end{tabular}

The total porosity of the samples $(\mathrm{W}, \%$ rel) was calculated taking into account the available literature data on the average values of true density of organic gels $\left(\rho_{\text {true }}, \mathrm{g} / \mathrm{cm}^{3}\right)$, close to $1,41[2,10]$. Based on these approximation, the calculation formula was applied: $\mathrm{W}=1-$ $\left(\rho_{\text {app }} / \rho_{\text {true }}\right)$. Calculated values of apparent density and total porosity of the obtained organic gels very widely, as in the case of gels synthesized using other phenolic sources. For example, the apparent density of resorcinol-formaldehyde organic gels are varied between $0.04-1.0 \mathrm{~g} / \mathrm{cm}^{3}$ [1], of phenol-formaldehyde gels - between 0.29 and $1.17 \mathrm{~g} / \mathrm{cm}^{3}$ [24].

Organic aerogels, prepared from phenol and furfural by two-step gelling first with $\mathrm{NaOH}$ and then with $\mathrm{HCl}$, have the apparent density $0.16-0.43 \mathrm{~g} / \mathrm{cm}^{3}$ [25]. The values of apparent density for organic gels, obtained from mixture of formaldehyde and birch bark tannins are 0.44$0.51 \mathrm{~g} / \mathrm{cm}^{3}[1]$.

The impact of ethanol lignin on the density and porosity of the organic gels synthesized from mixtures of formaldehyde and fir tannins was studied. An increase in ethanol lignin content in reaction mixture of less $50 \%$ mass has practically no effect on the density and porosity of the 
resulting gels. However, a further increase in the lignin concentration to $50-80 \%$ leads to a significant reduction in the density of gel (by 2-6 times) and to an increase of its total porosity (near 2 times).

The sample of xerogels synthesized from the mixture containing 50\% mas of ethanol lignin has minimum value of density $\left(0.11 \mathrm{~g} / \mathrm{cm}^{3}\right)$.

Samples of TLF gels with a high content of ethanol-lignin are loose, light and flexible materials. They retain their original shape during drying, and are resistant to shrinkage and compression. However, they do not have sufficiently high mechanical strength. The yield of the gel is very small at a significant content of lignin in the initial mixture ( $80 \%$ mass). No gel is formed from the ethanol lignin-formaldehyde mixture, but adding even a small amount of tannins ( $20 \%$ by weight) leads to the formation of gel.

Data on elemental composition and surface area of TF and TLF organic gels are given in Table 3. The carbon content in TLF gels is higher as compared to TF gels, since the relative content of carbon in ethanol lignin (66.3\%) is higher than in tannins $(57.7 \%)$.

Table 3. Elemental composition (\% ) and specific surface area $\left(\mathrm{S}_{\mathrm{SSA}}\right)$ of organic gels

\begin{tabular}{|l|l|l|l|}
\hline Gel sample & $\mathrm{C}, \%$ & $\mathrm{H}, \%$ & $\mathrm{~S}_{\mathrm{SSA}}, \mathrm{m}^{2} / \mathrm{g}$ \\
\hline TF $(\mathrm{HCl})^{*}$ & 60,94 & 5,12 & 8,9 \\
\hline TF $(\mathrm{NaOH})$ & 60,30 & 5,74 & 20,3 \\
\hline TF $(\mathrm{HCOOH})$ & 60,67 & 6,10 & 3,5 \\
\hline TLF, T/ L =1:0,25(HCl) & 62,68 & 5,60 & 1,5 \\
\hline TLF $; / \mathrm{L}=1: 0,5(\mathrm{HCl})$ & 63,48 & 5,38 & 0,6 \\
\hline TLF, T/ L =1:1(HCl) & 62,78 & 5,36 & 1,0 \\
\hline TLF, T/ L $=1: 2(\mathrm{HCl})$ & 65,29 & 5,52 & 1,4 \\
\hline
\end{tabular}

* acidic and alkali additive

The increase of $\mathrm{pH}$ of the reaction mixture in the presence of $\mathrm{NaOH}$ promotes the development of the porosity in the resulting organic TF gel. However, a mechanically fragile gel is formed which transforms to a brick-red powder after drying.

The structure of tannin-formaldehyde organic gels was studied by scanning electron microscopy at magnification 10,000 and 45,000 times. Figure 1a demonstrates the typical dendritic structure of a tannin-formaldehyde xerogel sample $(\mathrm{T} / \mathrm{F}=1.0 / 1.5 ; \mathrm{HCl})$. The xerogel has an open extended cellular structure formed by homogeneous particles.

Swirling chains of closely related nodules of particles with size smaller than $0.5 \mathrm{~mm}$ form the cavities ranking in size from 0.2 to $0.5 \mathrm{~mm}$.

The magnification of the image (Fig. 1-b) makes it possible to see that the nodules are ensembles of smaller particles twisted into tangles. 


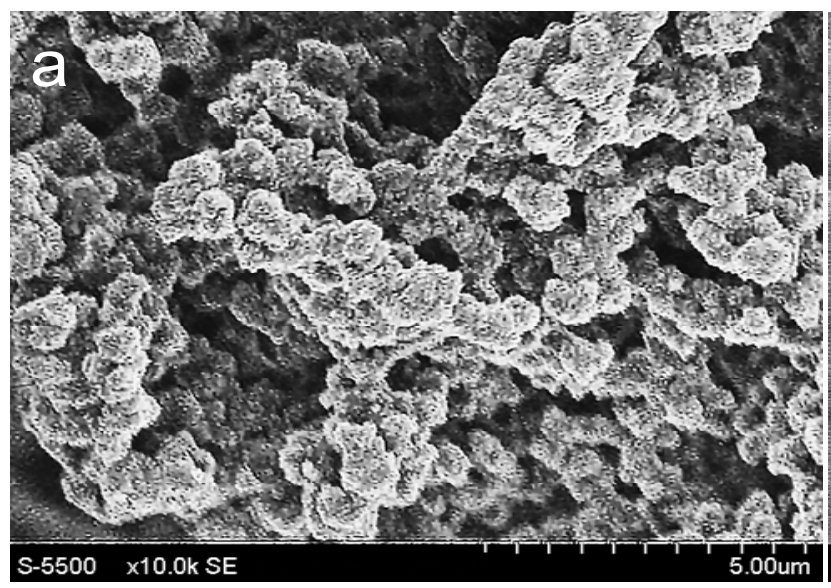

$\mathrm{a}-$ zoom 10000 times

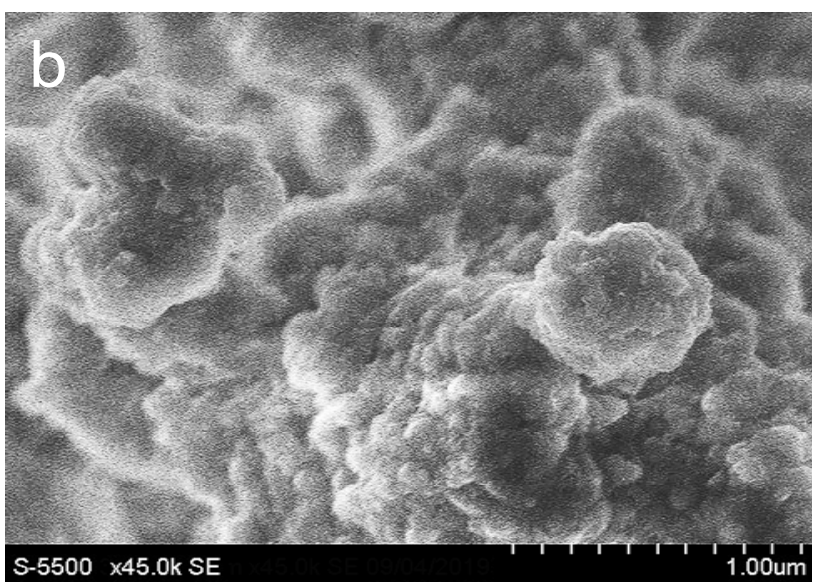

б - zoom 45000 times

Рис. 1. SEM-image of the sample of organic tannin-formaldehyde xerogel $(\mathrm{T} / \mathrm{F}=1.0: 1.5)$.

Thus, the process of condensation of tannins with formaldehyde leads to the formation of a three-dimensional cross-linked framework formed by nodules of micro or nanoparticles. The same structure was observed for other gels described in the literature $[2,10,26]$.

The morphology of TLF organic gels differs from those of tannin-formaldehyde gels (Fig. 2). Since lignin macromolecules are much larger than molecules of tannins, this leads to the formation of cavities of $5-10 \mu \mathrm{m}$ in sizes between connected chains of spherical particles of different size. Lignin macromolecules dispersed in the gel matrix are involved in the formation of a cross-linked structure, giving bulk properties and flexibility to the resulting gel.

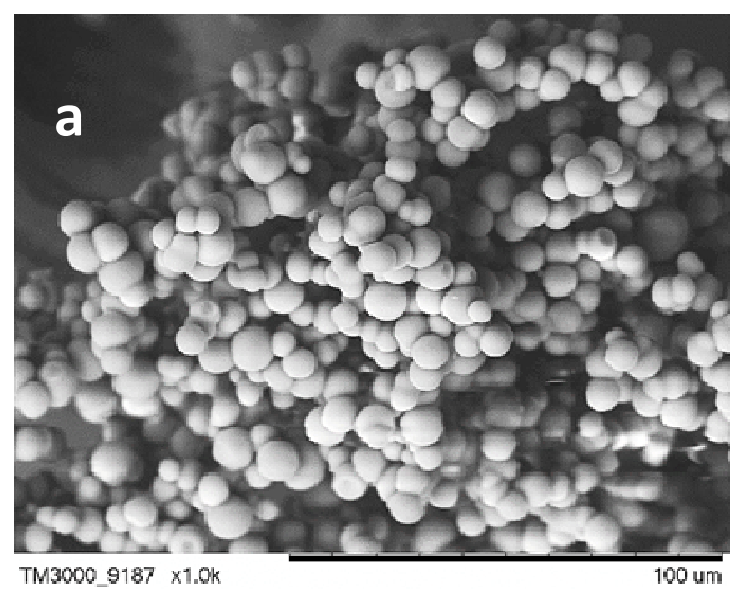

$\mathrm{a}-\mathrm{T} / \mathrm{L}=1.0: 0.5$

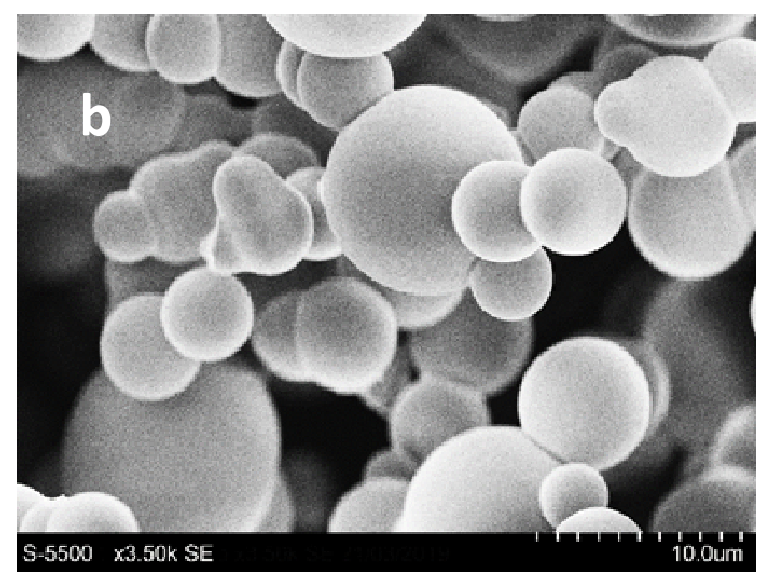

$\mathrm{b}-\mathrm{T} / \mathrm{L}=1: 1$

Fig. 2. SEM images of samples of organic tannin-lignin-formaldehyde xerogels: a - T / L $=1.0$ : 0.5, zoom 1.000x; b $-\mathrm{T} / \mathrm{L}=1: 1$, zoom 3500x.

A similar regularities were observed in the synthesis of lignin-resorcinol-formaldehyde organic aerogels [23]. 
The appearance of large particles in the gel contributes to a reduction in capillary pressure in the pores, which increase the flexibility of the skeleton, the elasticity of the gel and its resistance to deformation [23]. A high concentration of lignin in the initial mixture slows down the process of gelation. An increase in the density and a reduction in the porosity of TLF gels at an increase in the lignin content to $67-80 \% \mathrm{wt}$ can be explained by the fact that phenolic groups of lignin act as additional crosslinking agents, participating in condensation reactions [25]. A distinctive feature of the tannin-lignin-formaldehyde gel is the formation of spherical particles with a smooth non-porous surface (Fig. 3).

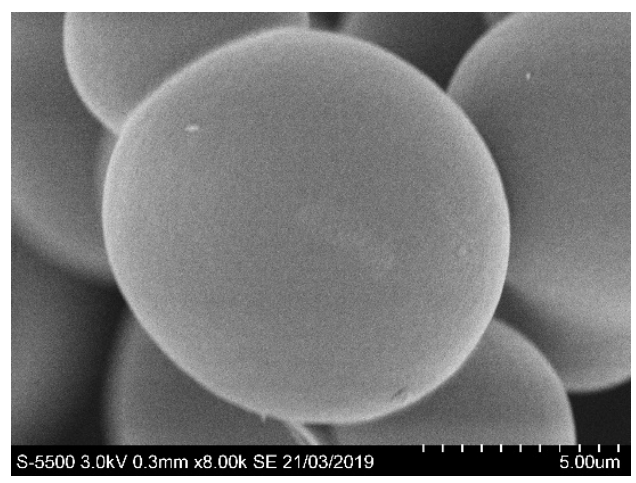

Fig.3 SEM image of the globular particles in TLF xerogel $(1: 1,800 \mathrm{x}$ zoom)

The information on the qualitative composition of the functional groups of organic TF and TLF gels was obtained by FTIR spectroscopy. FTIR spectra of samples of fir tannins and tannin-formaldehyde organic gel are presented in Fig. 4.

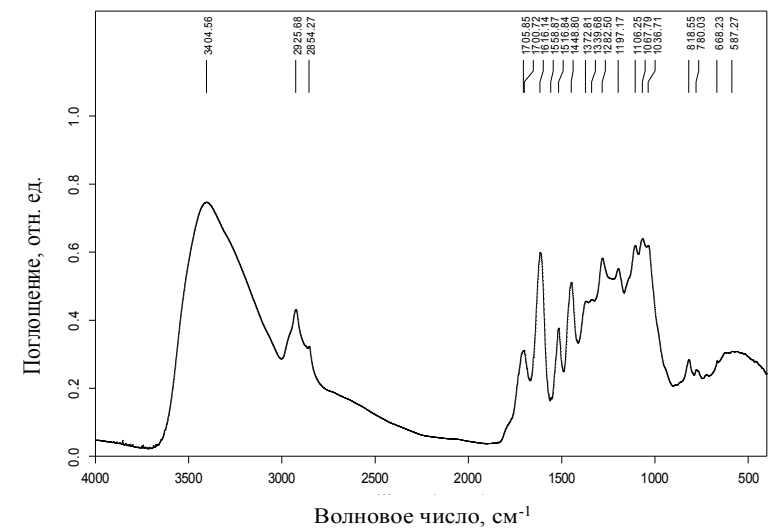

1

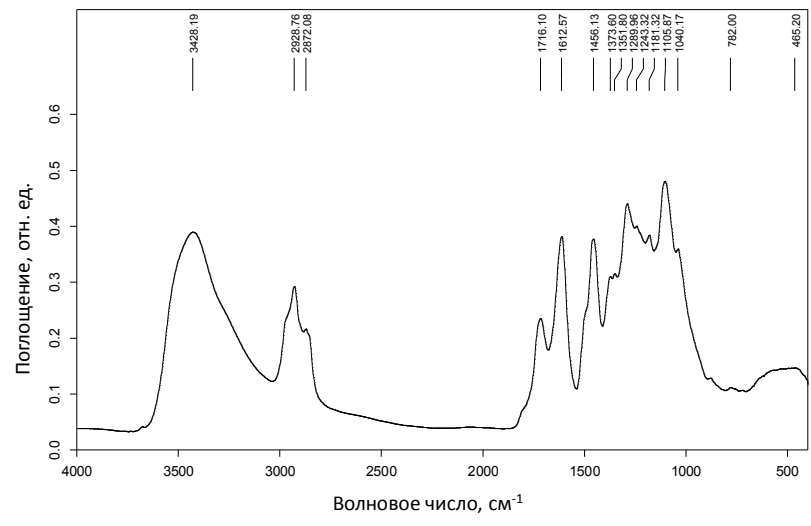

2

Fig. 4. FTIR spectra of samples of tannins of fir bark (1) and tannin-formaldehyde organic xerogel obtained from tannins of fir bark (2).

From a comparsion of these spectra, it follows that in TF gel sample the intensity of absorption bands at 2929 and $2872 \mathrm{~cm}^{-1}$ which correspond to stretching vibrations of C-H bonds in methyl and methylene groups is higher than in the initial tannins sample. This is apparently due to the formation of $-\mathrm{CH}_{2}-$ and $-\mathrm{CH}_{2}-\mathrm{O}-\mathrm{CH}_{2}-$ bonds in the interaction of formaldehyde 
with phenolic and OH-groups of tannins, that crosslink aromatic units in the process of polycondencation [13].

The absence in the spectrum of a TF gel of absorption bands in the region of 876-780 $\mathrm{cm}^{-1}$ corresponding to out-of-plane deformation vibrations of $\mathrm{C}-\mathrm{H}$ bonds in 1,3-substituted aromatic rings of tannins may indicate a change in the degree and nature of their substitution compared to the original tannins. According to [13], this can occurs as a result of a reactions of crosslinking with formaldehyde.

FTIR spectra of TLF gel (Fig.5) contain bands at 1503, 1275, and $1034 \mathrm{~cm}^{-1}$ that typical for lignin of guaiacyl type[28].

Obviously, the resulting TLF gel is a copolymer of tannin and lignin macromolecules.

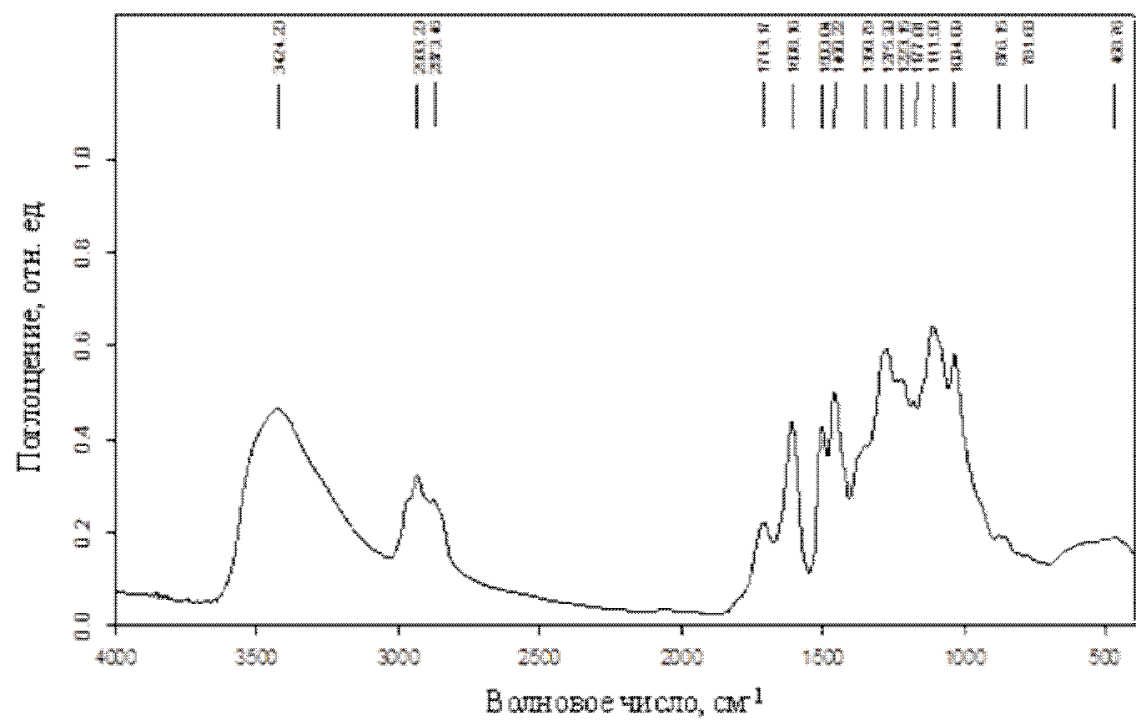

Fig. 5. FTIR spectrum of organic TLF xerogel (1: 1), obtained from fir polyphenols.

Tannin-formaldehyde gels obtained with the use of tannins of fir bark are materials with a typical structure of organic resorcin-formaldehyde [29] and queberacho tannin-formaldehyde gels $[2,13]$.

The study of the morphology of the obtained xerogels by SEM with a significant increase (45000x) confirmed the presence of a nodules structure of closely related micro- and nanoparticles, which is usually observed for most of the xerogels described in the literature.

The use of ethanol lignin as a co-agents makes possible to obtain TLF xerogels with low bulk density by varying the mass ratios of tannins and lignin. The lowest density of gel $(0.11$ $\mathrm{g} / \mathrm{cm}^{3}$ ) was observed at the equal mass ratio of tannins and ethanol lignin in the reaction mixture. Aerogels obtained under conditions of supercritical drying of lignin-resorcin-formaldehyde $(0.24$ $\left.\mathrm{g} / \mathrm{cm}^{3}\right)$ [23] and tannin-lignin [10] gels had a similar bulk density values $\left(0.24\right.$ and $0.19 \mathrm{~g} / \mathrm{cm}^{3}$, respectively). However, the density values of the xerogels obtained in this work are significantly 
lower than that of the resorcinol-formaldehyde xerogels which have a minimum density of 0.42 $\mathrm{g} / \mathrm{cm}^{3}[22]$.

According to $[10,22,23]$, lignin contributes to the reduction of gel shrinkage at drying stage and imparts a particles features to morphology of the nodule particles forming a gel structure. The particles have an almost perfect spherical shape and are practically smooth and non-porous. A similar effect of lignin was observed in the case of resorcin-lignin-formaldehyde and tannin-lignin-formaldehyde gels [2.4 10.23].

Organic gels may differ in thermal stability due to differences in their composition and structure $[11,30]$. The thermal stability of the obtained TF and TLP of organic gels was studied in an argon atmosphere by the method of thermogravimetry. Samples of TF and TLF gels (curve 2) have only one broad peak at $393.3-393.8^{\circ} \mathrm{C}$ on the DTG curve (Fig. 6).

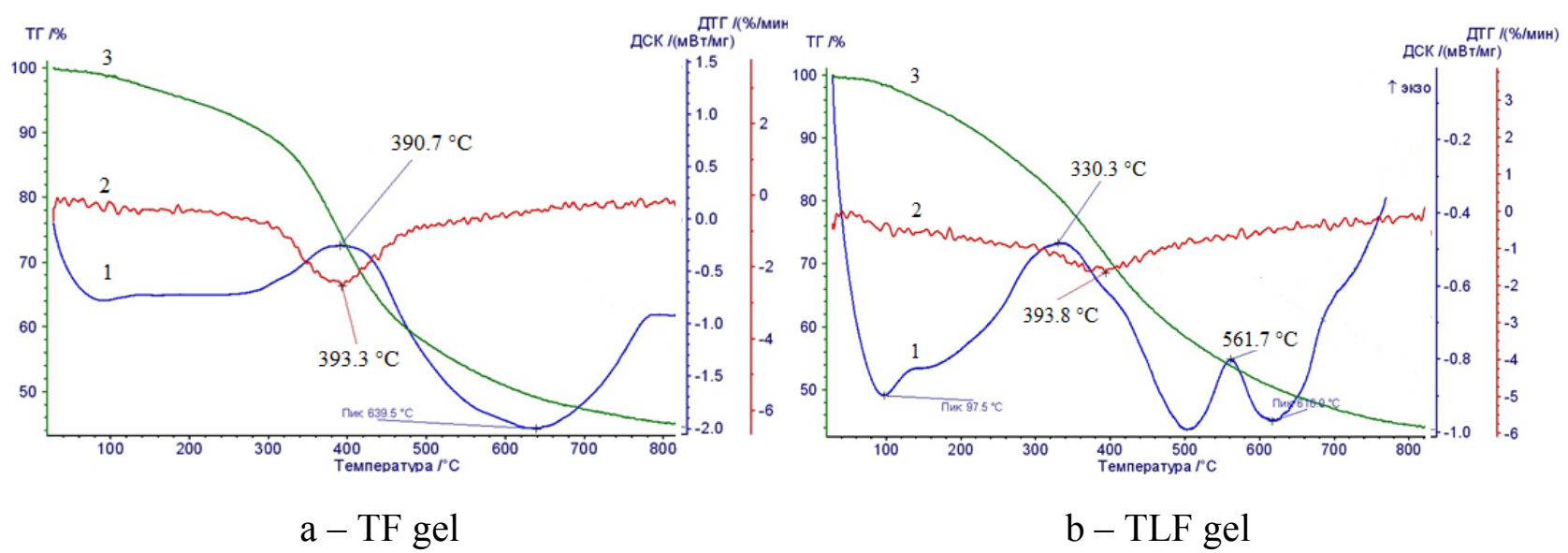

Fig. 6. Thermograms of TF (a) and TLF (1:2) xerogels obtained from fir polyphenols

For the TF gel sample (Figure 6-a), there is a coincidence of temperature maxima on the DTG $\left(393.3^{\circ} \mathrm{C}\right)$ and DSC $\left(390.7^{\circ} \mathrm{C}\right)$ curves. This may indicate a similar thermal decomposition of the gel components [31]. An intense endoeffect on DSC curve (broad peak at $640{ }^{\circ} \mathrm{C}$ ) probably indicates the formation of a carbonized residue. Its yield reaches to $45.15 \%$ with a rise of temperature to $800{ }^{\circ} \mathrm{C}$. In the case of TLF gel sample (Fig. 6-b), the lack of coincidence of temperature maxima on the DTG and DSC curves $\left(393.8^{\circ} \mathrm{C}\right.$ and $\left.330.3{ }^{\circ} \mathrm{C}\right)$ respectively and the presence of several alternating endo-and exo effects indicates that the decomposition of the gel components - tannins and lignin occurs in different temperature ranges.

The presence of lignin in TLF gel expands the range of its thermal transformations compared to TF gel. At the same time, with an increase in the content of lignin in the organic gel, the temperature of the onset of intense thermal decomposition and weight loss is decreased. 
Table 4 presents the main characteristics of the process of thermal decomposition of TF and TLF gels - conditional thermal intervals $\left({ }^{\circ} \mathrm{C}\right)$, average rates of mass loss in these intervals $(\mathrm{V}, \% / \mathrm{min})$ and value of mass loss $(\nabla \mathrm{m}, \%)$.

Table 4. Characteristics of the main stages of thermal decomposition of organic xerogels derived from fir polyphenols

\begin{tabular}{|c|c|c|c|c|c|}
\hline \multicolumn{6}{|c|}{ TF organic gels } \\
\hline Range, ${ }^{\circ} \mathrm{C}$ & $\leq 148$ & $148-295$ & $295-480$ & $480-800$ & \multirow[t]{3}{*}{ residue } \\
\hline$\nabla \mathrm{m}, \%$ & 3,0 & 7,0 & 30,9 & 13,95 & \\
\hline $\mathrm{V}, \% / \mathrm{min}$ & $-0,26$ & $-0,47$ & $-1,67$ & -0.43 & \\
\hline \multicolumn{6}{|c|}{ TLF organic gel (50\% lignin) } \\
\hline Range, ${ }^{\circ} \mathrm{C}$ & $\leq 125$ & $125-272$ & $272-480$ & $480-800$ & \multirow{3}{*}{$\begin{array}{c}\text { residue } \\
38,2 \\
\end{array}$} \\
\hline$\nabla \mathrm{m}, \%$ & 3,0 & 7,0 & 36,0 & 16,8 & \\
\hline $\mathrm{V}, \% / \mathrm{min}$ & $-0,32$ & $-0,47$ & $-1,72$ & $-0,51$ & \\
\hline \multicolumn{6}{|c|}{ TLF organic gel (67\% lignin) } \\
\hline Range, ${ }^{\circ} \mathrm{C}$ & $\leq 125$ & $125-232$ & $232-480$ & $480-800$ & \multirow[t]{3}{*}{ residue } \\
\hline$\nabla \mathrm{m}, \%$ & 3,0 & 6,96 & 30,0 & 15,6 & \\
\hline $\mathrm{V}, \% / \mathrm{min}$ & $-0,32$ & $-0,65$ & $-1,2$ & $-0,47$ & \\
\hline
\end{tabular}

As follows from the analysis of the obtained data, the process of mass loss by xerogels proceeds through several stages. For all samples, the initial stage of mass loss (about 3\%) in the temperature range $125-150^{\circ} \mathrm{C}$ takes place in the endothermic region with low mass loss rates ($0.26-0.32 \% / \mathrm{min})$. This is probably due to the removal of residual solvent from the porous of the gel. Significant mass loss of TF gel begins at a higher temperature (at $295^{\circ} \mathrm{C}$ ) then TLF gels containing 50 and $67 \%$ lignin (at 272 and $232^{\circ} \mathrm{C}$, respectively). The intensive mass loss of TLF gel samples is basically completed to a temperature of $480^{\circ} \mathrm{C}$.

A sample of TLF gel containing $50 \%$ of lignin loses the more mass in the temperature range up to $480^{\circ} \mathrm{C}$ and forms a carbonized residue with a lower yield (38.2\%) than a sample of TLF gel (44.4\% ) with a higher content of lignin (67\%).

It was found that the obtained organic TF and TLF gels are not combustible materials even at high temperatures $\left(600^{\circ} \mathrm{C}\right)$. In the presence of air, they do not burn, but are gradually transformed into carbonaceous material. Due to such thermal properties, these gels have prospects for the use as flame retardant materials.

\section{Conclusion}

For the first time it is proposed to use for the synthesis of organic gels a new renewable source of natural polyphenolic compounds - tannins and ethanol lignin, isolated from fir whose resources are large in many countries. 
New types of organic gels (xerogels) were obtained by condensation with formaldehyde of tannins and ethanol lignin isolated from fir bark and wood.

Tannin-formaldehyde gels obtained in an acidic medium are harder and stronger than gels obtained in an alkaline medium. However, they have increased brittleness and are prone to cracking when dried in vacuum. Bulk density and total porosity of organic gels can be controlled by adding lignin to the reaction mixture in ratios of 0.2 to 2.0 .

The formation of TLF gel with the lowest apparent density $\left(0.11 \mathrm{~g} / \mathrm{cm}^{3}\right)$ is observed at the lignin concentration in the reaction mixture $50 \%$. The addition of ethanol lignin improves the bulk properties and flexibility to the obtained TLF gels.

Fir ethanol lignin which characterized by a homogeneous composition and the absence of sulfur and mineral impurities is a good alternative to technical lignins in the production of organic and carbon gels.

The good solubility of tannins and ethanol lignin and their close molecular weights (1880 and $1740 \mathrm{~g} / \mathrm{mol}$, respectively) provide the formation of homogeneous solutions, which promotes the condensation reactions with formaldehyde and the formation of homogeneous TLF gels.

FTIR study confirmed the formation of $-\mathrm{CH}_{2}-$ and $-\mathrm{CH}_{2}-\mathrm{O}-\mathrm{CH}_{2}-$ bonds in the process of xerogels formation. It was shown by SEM that the TF gel has is a three-dimensional crosslinked framework formed by nodules of micro or nanoparticles. For TLF gels, unlike TF gels, an increase in the size of dense spherical particles is forming a three-dimensional cellular structure and cavities $5-10 \mu \mathrm{m}$ in size is observed.

Tannin-formaldehyde gels are more thermally stable than tannin-lignin-formaldehyde gels. There organic gels are non-flammable polymers and have potential for the use as flame retardant materials.

Available and non-toxic tannins and ethanol-lignin, extracted from renewable fir biomass, are an alternative to petroleum derived resorcinol and phenol used in the synthesis of organic and carbon gels.

The reported study was supported by Russian Science Foundation, grant N 16-13-10326.

\section{Reference}

1. Tao Y., Endo M., and Kaneko K. A Review of Synthesis and Nanopore Structures of Organic Polymer Aerogels and Carbon Aerogels //Recent Patents on Chemical Engineering. 2008. Vol. 1. P. 192-200. DOI: 10.2174/2211334710801030192

2. Amaral-Labat G., Grishechko L.I., Fierro V., Kuznetsov B.N., Pizzi A., Celzard A. Tanninbased xerogels with distinctive porous structures.// Biomass and bioenergy. 2013. Vol. 56. P.437-445. DOI: 10.1016/j.biombioe.2013.06.001

3. Lacoste C., Basso M.C., Pizzi A., Laborie M.P., Celzard A., Fierro V. Pine tannine based rigid foams: mechanical and thermal properties// Ind Crops Prod. 2013. Vol. 43. P.245-250. DOI: 10.1016/j.indcrop.2012.07.039 
4. Wu D, Fu R, Zhang S, Dresselhaus MD, Dresselhaus G. Preparation of low-density carbon aerogels by ambient pressure drying// Carbon. 2004. Vol. 42. N. 10. P. 2033-2039. DOI:

10.1016/j.carbon.2004.04.003

5. Job N., Thery A., Pirard R., Marien J., Kocon L., Rouzaud J.N., Beguin F., Pirard J-P. Carbon aerogels, cryogels and xerogels: influence of the drying method on the textural properties of porous carbon materials// Carbon. 2005. Vol. 43. N. 12. P. 2481-2494. DOI:

10.1016/j.carbon.2005.04.031

6. Moreno-Castilla C., Maldonado-Hodar F. J. Carbon aerogels for catalysis applications: an overview// Carbon. 2005. Vol. 43(3). P. 455-465.

7. Celzard A, Fierro V, Amaral-Labat G. Adsorption by carbon gels. In: Tascon JMD, editor. Novel carbon adsorbents. Oxford: Elsevier; 2012. p. 207-244

8. Lee Y.J., Jung J.C., Yi J., Baeck S.H., Yoon J.R., Song I.K. Preparation of carbon aerogel in ambient conditions for electrical doubleelayer capacitor. Curr Appl Phys 2010;10(2):682-686,

9. Li J, Wang X, Huang Q, Gamboa S, Sebastian PJ. Studies on preparation and performances of carbon aerogel electrodes for the application of supercapacitor// J Power Source. 2006. Vol. 158(1). P. 784-788

10. Grishechko L.I, Amaral-Labat G., Szczurek A., Fierro V., Kuznetsov B.N., Celzard A. Lignin - phenol - formaldehyde aerogels and cryogels// Micropor Mesopor Mater. 2013. Vol. 168. P. 19-29. DOI: 10.1016/j.micromeso.2012.09.024

11. Mikova N. M., Grishechko L. I., Skvortsova G. P., and B. N. Kuznetsov. Polyphenols of Wood Bark: Organic Precursors for the Production of Polymer Aerogels// Russian Journal of Bioorganic Chemistry, 2018, Vol. 44(7). P. 845-853

12. Duval A., Averous L. Characterization and physico-chemical properties of condensed tannins from Acacia catechu// Journal of Agricultural and Food Chemistry. 2016. Vol. 64. N. 8. P. 17511760. DOI: $10.1021 /$ acs.jafc.5b05671

13. Szczurek A, Amaral-Labat G, Fierro V, Pizzi A, Celzard A. The use of tannin for preparing carbon gels. Part II. Carbon cryogels. Carbon 2011. Vol. 49(8). P. 2785-2794.

14. Delgado-Sánchez C., Amaral-Labat G., Grishechko L.I., Sánchez -Sánchez A., Fierro V., Pizzi A. and Celzard A. Fire-resistant tannin-ethylene glycol gels working as rubber springs with tuneable elastic properties//J. Mater. Chem. A. 2017. Vol. 5(28). P. 14720-14732. DOI:

10.1039/C7TA03768F

15. Garnier S., Pizzi A., Vorster O. C., Halasz L. Rheology of Polyflavonoid TanninFormaldehyde Reactions Before and After Gelling. I. Methods// Journal of Applied Polymer Science. 2002. Vol. 86. P. 852-863

16. Scioneaux A.N., Schmidt M.A., Moore M.A., Lindroth R.L., Wooley S.C., Hagerman A.E.. Qualitative Variation in Proanthocyanidin Composition of Populus Species and Hybrids:

Genetics is the Key// J Chem Ecol. 2011. Vol. 37.P. 7-70. DOI 10.1007/s10886-010-9887-y. 17. Diouf P.N., Tibirna C.M., Garcia-Perez M-E., Rouer M., Dube P., Stevanovic T. Structural elucidation of condenced tannin from Picea mariana bark. Journal of Biomaterials and Nanobiotechnology. 2013. Vol.4. P.1-8

18. Nihat S. Cetin, Nilgul Ozmen. Use of organosolv lignin in phenol-formaldehyde resins for particleboard production I. Organosolv lignin modified resins //International Journal of Adhesion \& Adhesives. 2002. Vol. 22 P. 477 - 480. DOI: нет 
19. Wang M., Leitch M., Xu Ch. Synthesis of phenol-formaldehyde resol resins using organosolv pine lignins // European Polymer Journal. 2009. Vol. 45. P. 3380-3388. DOI: 10.1016/j.eurpolymj.2009.10.003

20. Weinwurm F., Drljo A., Silva T.L.S., Friedl A. Principles of ethanol organosolv lignin precipitation: process simulation and energy demand// Chemical Engineering Transactions. 2014. Vol. 39. P. 583-588. DOI: 10.3303/CET1439098

21. Per Tomani. The LignoBoost Process// Cellulose Chem. Technol., 44 (1-3), 53-58 (2010)

22. Chris D. Castro and Germán C. Quintana. Mixture Design Approach on the Physical Properties of Lignin-Resorcinol-Formaldehyde Xerogels// Intern Journal of Polymer Science. Volume 2015, Article ID 272851, 11 pages. http://dx.doi.org/10.1155/2015/272851

23. Chen F., Xu M., Wang L., Li J. Preparation and characterization of organic aerogels from a lignin-resorcinol-formaldehyde copolymer// BioResources.com. 2011. Vol. 6. N. 2. P. 12621272.

24. Scherdel C., Reichenauer G. Carbon xerogels synthesized via phenol-formaldehyde gels// Microporous and Mesoporous Materials. 2009. Vol. 126. P.133-142

25. Dingcai Wu., Ruowen Fu. Synthesis of organic and carbon aerogels from phenol-furfural by two-step polymerization// Microporous and Mesoporous Materials. 2006. Vol. 96. P. 115-120. 26. Wu D., Fu R., Sun Z., Yu Z. Low-density organic and carbon aerogels from the sol-gel polymerization of phenol with formaldehyde// J. Non-Crystalline Solids. 2005. Vol. 351, P. 915919. DOI: $10.1016 /$ j.jnoncrysol.2005.02.008

27. Derek Stewart. Lignin as a base material for materials applications: Chemistry, application and economics// Ind Crops Prod. 2008. Vol. 27. P. 202-207. DOI: 0.1016/j.indcrop.2007.07.008 28. Tejado A., Peña C., Labidi J., Echeverria J.M., Mondragon I. Physico-chemical characterization of lignins from different sources for use in phenol-formaldehyde resin synthesis // Bioresource Technology. 2007. Vol. 98. P. 1655-1663. DOI: 10.1016/j.biortech.2006.05.042 29. Pekala, R.W., 1989. Organic aerogels from the polycondensation of resorcinol with formaldehyde. Journal of Materials Science 24, 3221-3227.

30. Amaral-Labat G., Szczurek A., Fierro V., Pizzi A., Celzard A. Systematic studies of tanninformaldehyde aerogels: preparation and properties// Sci Technol Adv Mater. 2013 Vol. 14(1): 015001. DOI: 10.1088/1468-6996/14/1/015001

31. M. Kijima, T. Hirukawa, F. Hanawa, T. Hata. Thermal conversion of alkaline lignin and structured derivatives to porous carbonized material// Bioresorce Technology. 2011. Vol. 102. P. 6279-6285. DOI: 10.1016/j.biortech.2011.03.023. 